\title{
What a great aortic surgeon would Messer Leonardo have been ...
}

\author{
Mario Gaudino, MD, and Leonard N. Girardi, MD
}

\author{
From the Department of Cardiothoracic Surgery, Cornell Medicine, New York, NY. \\ Disclosures: Authors have nothing to disclose with regard to commercial support. \\ Received for publication June 10, 2017; accepted for publication June 14, 2017. \\ Address for reprints: Mario Gaudino, MD, Department of Cardiothoracic Surgery, Weill Cornell Medical College, \\ 525 E 68th St, New York, NY 10065 (E-mail: mfg9004@med.cornell.edu). \\ J Thorac Cardiovasc Surg 2017;154:1219 \\ $0022-5223 / \$ 36.00$ \\ Copyright (c) 2017 by The American Association for Thoracic Surgery \\ http://dx.doi.org/10.1016/j.jtcvs.2017.06.032
}

Leonardo da Vinci was a physician, mathematician, engineer, and scientist in the broadest sense. He foresaw the flow dynamics in the aortic root well before computational flow dynamics (CD) and painted the Monna Lisa. It is high likely that, if he was alive today, he would have been interested in cardiothoracic surgery.

Thoracic aortic surgery is witnessing a revolution. Not more than 2 decades ago operations on the thoracic and thoracoabdominal aorta were heroic procedures attempted only by very few highly skilled surgeons, whose bravery was second only to that of their patients. Today, thanks to the dedication and acumen of those giants, treatment of diseases of the thoracic aorta has become standard practice, and in specialized centers the operative risk for repair of thoracic and thoracoabdominal aortic aneurysms has been reduced to a single digit. ${ }^{1,2}$

Simultaneously with the improvement in outcome, new technologies and methods have been applied to the study of the thoracic aorta. Scientists from different disciplines have worked together to elucidate the genetic and molecular basis of aortic diseases and to characterize their intrinsic pathophysiologic mechanisms. The idea that size is the only important parameter has been challenged repeatedly and a more complex and integrated vision of the aortopathies is replacing the old mechanistic approach.

CD studies (as in the example presented by Iida and colleagues $^{3}$ ) open a new perspective on the studies of the changes of blood flow in different parts of the aorta in various physiologic and pathologic conditions. In our laboratory, we are exploring the tremendous and fascinating potential of $\mathrm{CD}$ applied to the aortic root and the thoracoabdominal aorta, and we believe that $\mathrm{CD}$ will become an essential tool both for diagnosis and evaluation of the surgical repair.

However, it is probably worth reminding that in Leonardo's paintings, the beauty and apparent simplicity of the images is in fact the result of countless hours of rigorous observation and strict scientific method. Similarly, the beautiful pictures generated by $\mathrm{CD}$ cannot substitute the need for objective data to support their use. Penetrating

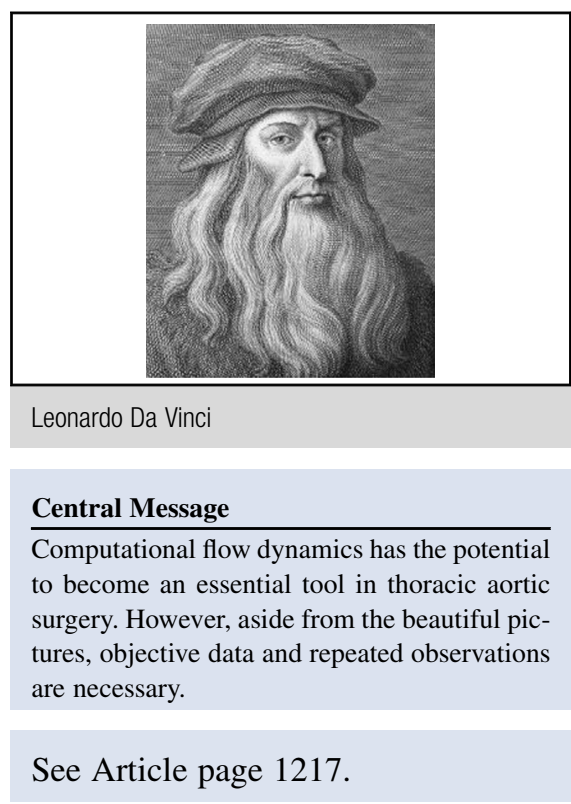

atherosclerotic ulcers (PAUs) are an area of aortic pathology in which there are very limited data on how threatening they are, what diameters predict rupture, and when should surgery be performed. CD probably can be instrumental in gathering more solid data on PAUs. It seems likely that flow into and out of the ulcer should somehow correlate with the pressure on the wall, and perhaps in the near future it will be possible not just to establish flow in the PAU but to also evaluate how much, if any, increase in either wall tension, wall pressure, or rate of rise of left ventricular pressure occurs inside these ulcers relative to these established values in the tubular and more laminar flow part of the aorta.

Clearly, the same level of genius of Leonardo is not required. However, the multidisciplinary knowledge, the intellectual curiosity, and the scientific method so highly expressed by Leonardo are probably the most important characteristics of the aortic surgeon of the new era.

\section{References}

1. Coselli JS, LeMaire SA, Preventza O, de la Cruz KI, Cooley DA, Price MD, et al Outcomes of 3309 thoracoabdominal aortic aneurysm repairs. J Thorac Cardiovasc Surg. 2016;151:1323-37.

2. Girardi LN, Lau C, Munjal M. Elsayed M, Gambardella I, Ohmes LB, et al. Impact of preoperative pulmonary function on outcomes after open repair of descending and thoracoabdominal aortic aneurysms. J Thorac Cardiovasc Surg. 2017;153: S22-9.

3. Iida Y, Yoshitake A, Shimizu H. Blood flow into ulcer-like projection of type B aortic dissection using computational fluid dynamics. J Thorac Cardiovasc Surg. 2017; 154:1217-8. 